\title{
Analysis, Design and Implementation of a New Chokeless Interleaved ZVS Forward-Flyback Converter
}

\author{
Meghdad Taheri ${ }^{\dagger}$, Jafar Milimonfared*, Alireza Namadmalan*, \\ Hasan Bayat*, and Mohammad Kazem Bakhshizadeh* \\ ${ }^{\dagger *}$ Dept. of Electrical Eng., Amirkabir University of Technology (Tehran Polytechnic), Tehran, Iran
}

\begin{abstract}
This paper presents an interleaved active-clamping zero-voltage-switching (ZVS) forward-flyback converter without an output choke. The presented topology has two active-clamping circuits with two separated transformers. Because of the interleaved operation of the converter, the output current ripple will be reduced. The proposed converter can approximately share the total load current between the two secondaries. Therefore, the transformer copper loss and the rectifier diodes conduction loss can be decreased. The output capacitor is made of two series capacitors which reduces the peak reverse voltage of the rectifier diodes. The circuit has no output inductor and few semiconductor elements, such that the adopted circuit has a simpler structure, a lower cost and is suitable for high power density applications. A detailed analysis and the design of this new converter are described. A prototype converter has been implemented and experimental results have been recorded with an ac input voltage of 85-135Vrms, an output voltage of $12 \mathrm{~V}$ and an output current of 16A.
\end{abstract}

Key Words: Active clamping circuit, Forward-flyback converter, Interleaved converter, Zero-voltage switching

\section{INTRODUCTION}

Forward and flyback converters have been widely used in the power supply industry because of their simplicity, good efficiency and low cost. The transformer in a flyback converter is used to isolate the electric signal and to store the magnetic energy. The transformer in a forward converter is adopted to achieve circuit isolation and energy transformation. The hard switching operation of forward and flyback converters imposes high voltage and current spikes on their switches, due to the presence of transformer leakage inductance. Furthermore, the switching losses result in a low conversion efficiency. A passive-clamping circuit can be added for dissipation of the stored energy in the leakage inductance [1], which reduces the voltage stress on the switch. However, the conversion efficiency of the converter will not be greatly improved. In recent years, active-clamping techniques have been proposed for both types of converters [2]-[14] to absorb the energy stored in the leakage inductance and to suppress the voltage spikes on the switch. Furthermore, in the forward converter, it completes the energy reset process. In comparison with conventional forward and flyback converters, the active-clamping converters have a

Manuscript received Jun. 6, 2010; revised Apr. 14, 2011

Recommended for publication by Associate Editor Yong-Chae Jung.

$\dagger$ Corresponding Author: meghdadtaheri@aut.ac.ir

Tel: +98-21-64543350, Amirkabir University of Technology

* Dept. of Electrical Eng., Amirkabir University of Technology (Tehran Polytechnic), Iran higher efficiency because of the zero-voltage-switching (ZVS) operation of the main switch, which is fulfilled with the help of the auxiliary switch. Unfortunately, the DC offset current of an active clamp flyback converter, deteriorates the transformer utilization and increases the transformer size, which results in the low power density of the converter.

The power losses and current stress on the switch devices can be evenly distributed by paralleling two or more converters. Using interleaved structures, the output current ripple can be significantly reduced, or equivalently, the output inductance and capacitance can be halved under the same output rating. However, in interleaved active-clamping converters a total of four switches, four diodes and more magnetic components including transformers and inductors are required, which increases the circuit size, complexity and cost [15]-[21].

This paper presents a new interleaved active-clamping zerovoltage-switching forward-flyback converter without an output choke. Two converter modules are connected in parallel on the input and output sides to reduce the current stresses on the output diodes and windings of the transformers. The main switch of any converter acts as an auxiliary switch for the other one. As a result, only two switches are required and there is no need for additional switches to achieve ZVS operation. The output capacitor is made of two series capacitors which reduces the reverse voltage of the rectifier diodes. The proposed circuit has no large output inductor. Therefore, the adopted circuit has a simpler structure, a lower cost and is capable of a high power 


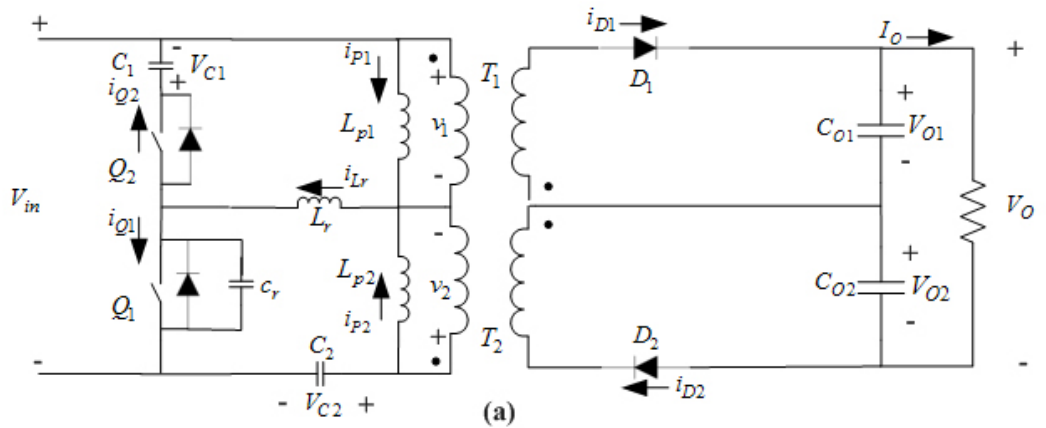

Fig. 1. Schematic of the proposed choke-less interleaved ZVS forward-flyback converter.

density. Based on the above mentioned reasons, the proposed converter is suitable for high-voltage and high-current output applications.

The circuit configuration, the principle of operation and the design considerations of the proposed converter are discussed in detail. Finally, experimental results based on a $180 \mathrm{~W}$ (12V/15A) prototype circuit are presented to verify the circuit performance.

\section{Circuit Configuration}

Fig. 1 shows a schematic of the proposed topology which is composed of an active-clamping forward converter parallel with an active-clamping flyback converter. The flyback converter includes $V_{i n}, T_{1}, Q_{1}, Q_{2}, C_{1}, D_{1}, C_{o 1}$ and $C_{o 2}$. Similarly, the forward converter consists of $V_{C 2}, T_{2}, Q_{1}, Q_{2}, C_{1}, D_{2}, C_{o 1}$ and $C_{o 2} . L_{r}$ is the sum of the leakage inductances of $T_{1}$ and $T_{2} . L_{P 1}$ and $L_{P 2}$ are the magnetizing inductances of $T_{1}$ and $T_{2}$. $V_{i n}$ and $V_{o}$ are the input voltage source and the output voltage, respectively. $C_{o 1}$ and $C_{o 2}$ are the output capacitors. $C_{r}$ is equivalent to the parallel combination of the output capacitances of $Q_{1}$ and $Q_{2}$ and the parasitic capacitances of the transformer primary windings. The auxiliary switch $Q_{2}$ and the clamp capacitor $C_{1}$ represent the active clamp circuit to absorb the surge energy due to the leakage inductance $L_{r}$.

\section{PRINCIPLES OF OPERATION}

Based on the on/off states of $Q_{1}, Q_{2}, D_{1}$ and $D_{2}$, the proposed converter has eight operating modes during one switching cycle. Fig. 2 depicts the key waveforms of the proposed converter. In the following analysis, the governing current and the voltage equations are derived for each state. The conduction paths for each operating state are shown in Fig. 3

State $1\left(t_{0}-t_{1}\right): Q_{1}$ is turned on. As shown in Fig. 3(a) for the flyback part, $v_{1}$ is $n_{\nu O 2}$ and $D_{1}$ is reverse biased. The input energy is stored in the primary magnetizing inductance $L_{P 1}$ and $i_{P 1}$ increases linearly. For the forward part, $v_{2}$ is $n_{v O 2}$. Thus, $i_{P 2}$ increases linearly. The diode $D_{2}$ is on and the input power is delivered to the secondary. In this state, the primary currents $i_{P 1}, i_{P 2}$ and resonant inductor current $i_{L r}$ can be expressed as:

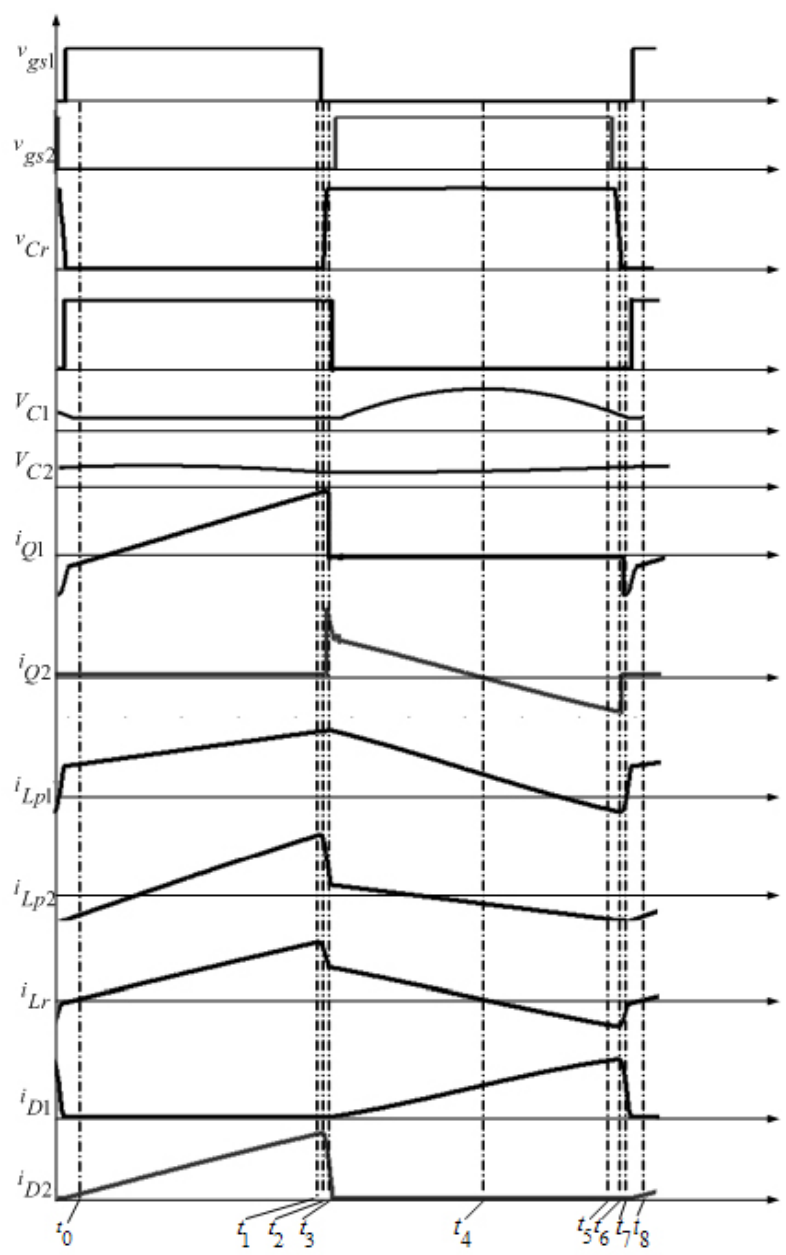

Fig. 2. Key waveforms of the proposed converter.

$$
\begin{aligned}
& i_{p 1}=\frac{n V_{O 2}}{L_{P}} t+i_{p_{1}}\left(t_{0}\right) \\
& i_{p 2}=\frac{n V_{O 2}}{L_{P}} t+\frac{i_{D 2}}{n}+i_{p 2}\left(t_{0}\right) \\
& i_{L r}=\frac{V_{i n}-n V_{O 2}}{L_{r}} t+i_{L r}\left(t_{0}\right) .
\end{aligned}
$$

State $2\left(t_{1}-t_{2}\right)$ : This state starts at $t_{1}$ when $Q_{1}$ is turned off. As shown in Fig. 3(b), for the flyback part $D_{1}$ is still off. The resonant inductor current $i_{L r}$ charges the resonant capacitor $C_{r}$ from zero to $V_{i n}+V_{C 1}$. For the forward part $i_{D 2}$ is linearly 

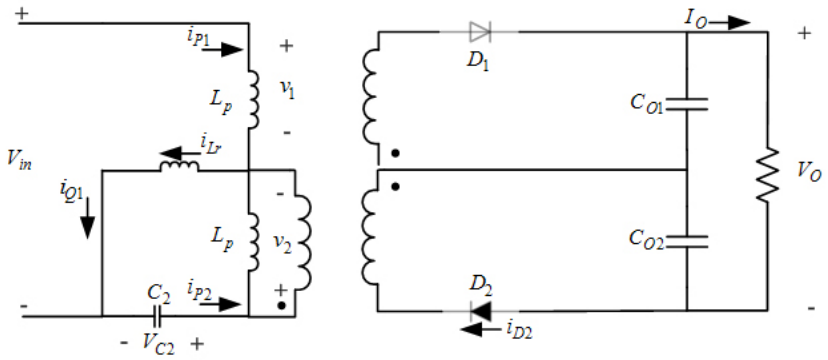

(a)
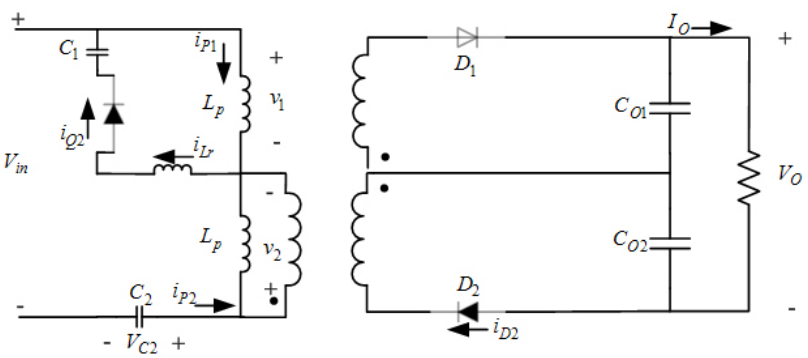

(c)
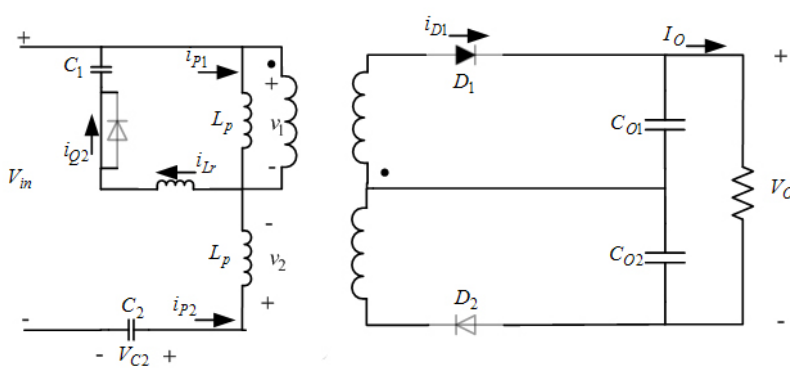

(e)
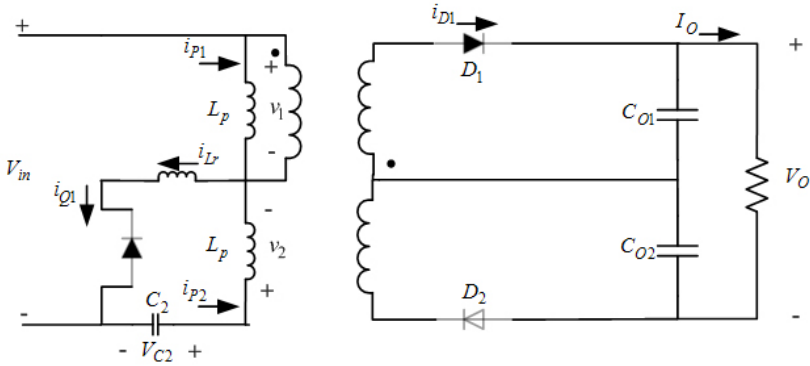

(g)
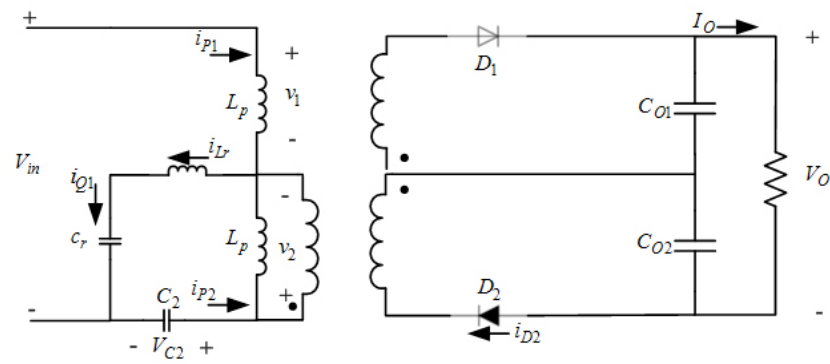

(b)
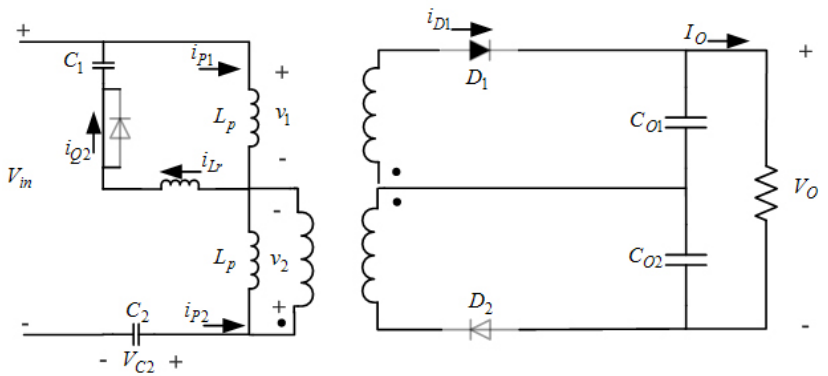

(d)
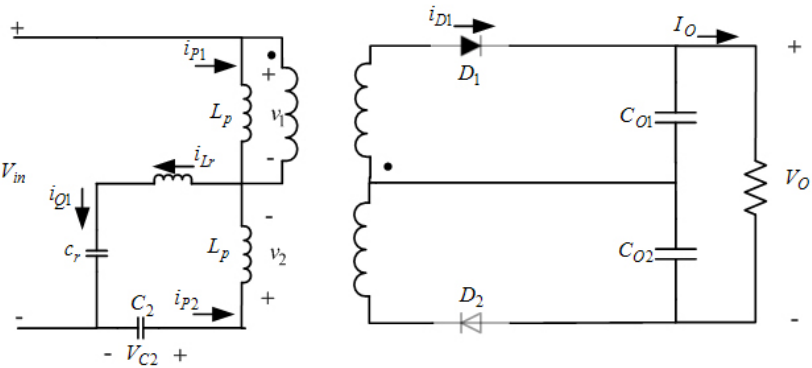

(f)
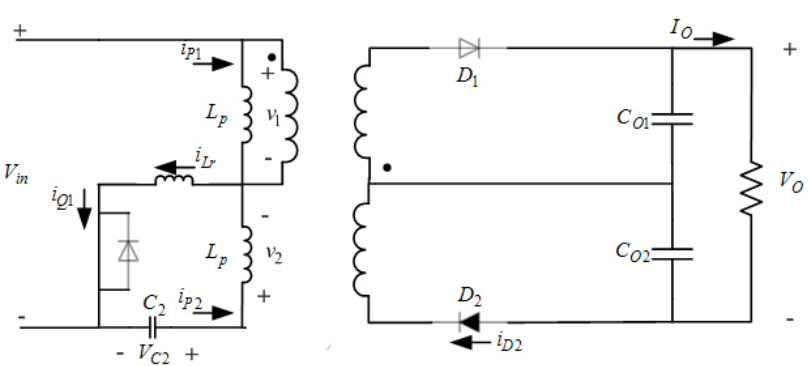

(h)

Fig. 3. Conduction paths of (a) state 1, (b) state 2, (c) state 3, (d) state 4, (e) state 5, (f) state 6, (g) state 7, and (h) state 8 for the proposed converter during one switching period.

decreasing. In this state, the resonant inductor current $i_{L r}$ and the resonant capacitor voltage $v_{C r}$ can be written as:

$i_{L r}=w_{0} C_{r}\left(V_{i n}-n V_{o 2}\right) \sin w_{0}\left(t-t_{1}\right)+i_{L r}\left(t_{1}\right) \cos w_{0}\left(t-t_{1}\right)$

$v_{C r}=\frac{i_{L r}\left(t_{1}\right)}{w_{0} C_{r}} \sin w_{0}\left(t-t_{1}\right)+\left(V_{i n}-n V_{o 2}\right)\left[1-\cos w_{0}\left(t-t_{1}\right)\right]$
Where

$$
w_{0}=\sqrt{\frac{1}{L_{r} C_{r}}} .
$$

The time interval of this state can be expressed as:

$$
\left(t_{2}-t_{1}\right)=\frac{C_{r}}{i_{L r}\left(t_{1}\right)}\left(V_{i n}+V_{C 1}\right) .
$$

State $3\left(t_{2}-t_{3}\right)$ : After $t_{2}$, the resonant capacitor voltage $v_{C r}$ is clamped at $V_{i n}+V_{C 1}$. For the flyback part $i_{P 1}$ is increasing and $D_{1}$ is still reverse biased. For the forward part $i_{P 2}$ and $i_{D 2}$ is linearly decreasing. The resonant inductor current $\mathrm{iLr}$ 
decreases linearly while flowing through the body diode of $Q_{2}$, as shown in Fig. 3(c), to charge the clamping capacitor $C_{1} . Q_{2}$ can now be turned on. Since $C_{1}$ is assumed to be much larger than $C_{r}, V_{C 1}$ remains almost constant. In this state, $i_{L r}$ can be written as:

$$
i_{L r}=i_{L r}\left(t_{2}\right) \cos w_{1}\left(t-t_{2}\right)-n V_{O 1} \sqrt{\frac{2 C_{1}}{L_{P}+2 L_{r}}} \sin w_{1}\left(t-t_{2}\right)
$$

Where

$$
w_{1}=\sqrt{\frac{2}{\left(L_{P}+2 L_{r}\right) C_{1}}} .
$$

This interval ends when $v_{1}$ and $v_{2}$ equal $\left(-n v_{O_{2}}\right)$ at $t_{3}$.

State $4\left(t_{3}-t_{4}\right)$ : As shown in Fig. 3(d), at $t_{3}, i_{D 2}$ decays to zero. $i_{D 1}$ is linearly increasing and the energy stored in $L_{P 1}$ is transferred to the output load. The resonant inductor $L_{r}$ and the clamping capacitor $C_{1}$ begin to resonate. In order to ensure the ZVS operation of $Q_{2}, Q_{2}$ should be turned on before it becomes negative. In this state, the primary currents $i_{P 1}$ and $i_{P 2}$ and resonant inductor current $i_{L r}$ can be expressed as:

$$
\begin{gathered}
i_{p 1=}-\frac{n V_{o 1}}{L_{P}}\left(t-t_{3}\right)-\frac{i_{D 1}}{n}+i_{p 1}\left(t_{3}\right) \\
i_{p 2=}-\frac{n V_{o 1}}{L_{P}}\left(t-t_{3}\right)+i_{p 2}\left(t_{3}\right) \\
i_{L r}=w_{2} C_{1}\left(n V_{O 1}-V_{C 1}\right) \sin w_{0}\left(t-t_{3}\right)+i_{L r}\left(t_{3}\right) \cos w_{0}\left(t-t_{3}\right)
\end{gathered}
$$$$
w_{2}=\sqrt{\frac{1}{L_{r} C_{1}}} .
$$

State 4 is accomplished when $i_{L r}$ is zero.

State $5\left(t_{4}-t_{5}\right)$ : The circuit operations in this interval are the same as those in State 4, except that the direction of $i_{L r}$ is reversed. As a result, $Q_{2}$ conducts instead of its body diode. This state is accomplished when $Q_{2}$ is turned off.

State $6\left(t_{5}-t_{6}\right)$ : The auxiliary switch $Q_{2}$ is turned off at $t_{5}$. The resonant capacitor $C_{r}$ is discharged via the current $i_{L r}$ at the same time. For the flyback part $D_{1}$ is still on and $v_{1}$ is $\left(-n v_{O 1}\right)$. For the forward part $v_{2}$ is $\left(-n v_{O 1}\right)$ and $D_{2}$ is reverse biased. The resonant current $i_{L r}$ and the resonant capacitor voltage $V_{C r}$ can be derived as:

$$
\begin{gathered}
i_{L r}=w_{0} C_{r}\left(V_{i n}+n V_{o 1}-v_{c r}\left(t_{5}\right)\right) \sin w_{0}\left(t-t_{5}\right) \\
+i_{L r}\left(t_{5}\right) \cos w_{0}\left(t-t_{5}\right) \\
v_{C r}=\frac{i_{L r}\left(t_{5}\right)}{w_{0} C_{r}} \sin w_{0}\left(t-t_{5}\right)- \\
\left(V_{i n}+n V_{o 1}-v_{c r}\left(t_{5}\right)\right) \cos w_{0}\left(t-t_{5}\right)+V_{i n} .+n V_{o 1}
\end{gathered}
$$

To ensure the ZVS operation for $Q_{1}$, the initial energy stored in $L_{r}$ must be greater than the energy stored in $C_{r}$. That is:

$$
\frac{1}{2} L_{r} i_{L r}^{2}\left(t_{5}\right) \geq \frac{1}{2} C_{r}\left(V_{i n}+V_{C 1}\right)^{2} .
$$

This state ends at $t_{6}$ when the voltage $V_{C r}$ decreases to zero.

State $7\left(t_{6}-t_{7}\right)$ : At $t_{6}, V_{C r}$ decreases to zero. As shown in Fig. 3(h), the body diode of $Q_{1}$ is conducting and $Q_{1}$ can be turned on to achieve the ZVS operation. For the flyback part v1 is $\left(-n v_{O 1}\right)$, but the secondary current through $D_{1}$ is linearly decreasing. For the forward part, $v_{2}$ is $\left(-n v_{O 1}\right)$ and $D_{2}$ is still reverse biased. In this state, the primary currents $i_{P 1}$ and $i_{P 2}$ and the resonant inductor current $i_{L r}$ can be expressed as:

$$
\begin{aligned}
& i_{p 1}=-\frac{n V_{o 1}}{L_{P}}\left(t-t_{6}\right)-\frac{i_{D 1}}{n}+i_{p_{1}}\left(t_{6}\right) \\
& i_{p 2}=-\frac{n V_{o 1}}{L_{P}}\left(t-t_{6}\right)+i_{p 2}\left(t_{6}\right) \\
& i_{L r}=\frac{V_{i n}+n V_{o 1}}{L_{r}}\left(t-t_{6}\right)+i_{L r}\left(t_{6}\right) .
\end{aligned}
$$

This state ends at $t_{7}$ when $Q_{1}$ is on.

State $8\left(t_{7}-t_{8}\right)$ : This stage begins at $t_{7}$ when $Q_{1}$ is turned on and ends at $t_{8}$ when $i_{D 1}$ equals zero. The equivalent circuit of this stage is the same as the equivalent circuit in stage 7 .

\section{Design Consideration}

Based on the voltage-second balance across the secondary side of $T_{1}$ and $T_{2}$, the output capacitor voltages are given as

$$
\begin{gathered}
V_{O 1}=D V_{O} \\
V_{O 2}=(1-D) V_{O} .
\end{gathered}
$$

Based on the voltage-second balance on the primary side of $T_{1}$ and $T_{2}$ the average clamp voltages $V_{c 1}$ and $V_{c 2}$ can be obtained as:

$$
\begin{gathered}
V_{C 1}=\frac{D}{1-D} V_{i n} \\
V_{C 2}=V_{i n} .
\end{gathered}
$$

Based on the voltage-second balance of the leakage inductances of $T_{1}$ and $T_{2}$, the voltage conversion ratio $M$ is expressed as

$$
M=\frac{V_{O}}{V_{\text {in }}}=\frac{1}{n(1-D)} .
$$

The turns ratio of the transformer primary winding to the secondary winding is equal to

$$
n=\frac{N_{P}}{N_{S}}=\frac{V_{i n, \min }}{\left(V_{o}+V_{f}\right)\left(1-D_{\max }\right)}
$$

where is $V_{f}$ the voltage drop of the rectifier diode. The maximum voltage stresses of $Q_{1}$ and $Q_{2}$ are approximated as

$$
V_{D S 1, \max }=V_{D S 2, \max }=V_{i n}+V_{C 1}=\frac{V_{i n}}{1-D} .
$$

The peak currents of $Q_{1}$ and $Q_{2}$ are expressed as

$$
I_{Q 1, \max }=I_{Q 2, \max }=2\left[\frac{I_{o, \text { max }}}{n}+\frac{V_{i n, \min }}{L_{P}} D_{\max } T_{S}\right] .
$$

To ensure the ZVS operation for $Q_{1}$, the initial energy stored in $L_{r}$ must be greater than the energy stored in $C_{r}$. That is:

$$
L_{r} \geq \frac{C_{r}\left(V_{i n}+n V_{C 1}\right)^{2}}{i_{L r}^{2}\left(t_{5}\right)} \simeq \frac{C_{r}\left(V_{i n}+V_{C 1}\right)^{2}}{i_{Q 1, \max }^{2}} .
$$

The voltage stresses of the secondary rectifier diodes are 


$$
V_{D 1, \max }=V_{D 2, \max }=V_{O} .
$$

This equation shows that the voltage stresses of the rectifier diodes reduces significantly in comparison to [20].

The peak secondary diode currents are expressed as

$$
I_{D 1, \max }=I_{D 2, \max }=2 I_{o, \max }
$$

The root mean square currents of the rectifier diodes are

$$
\begin{gathered}
I_{D 1, r m s}=\frac{2}{\sqrt{3}} I_{o, \max } \sqrt{1-D} \\
I_{D 2, r m s}=\frac{2}{\sqrt{3}} I_{o, \max } \sqrt{D} .
\end{gathered}
$$

If the current ripples of the magnetizing inductors are given, the magnetizing inductance can be obtained as

$$
\begin{gathered}
L_{P 1}=\frac{n V_{O 2} D T_{s}}{\Delta i_{L P 1}}=\frac{n V_{O}(1-D) D T_{s}}{\Delta i_{L P 1}} \\
L_{P 2}=\frac{n V_{O 1}(1-D) T_{s}}{\Delta i_{L P 2}}=\frac{n V_{O}(1-D) D T_{s}}{\Delta i_{L P 2}} .
\end{gathered}
$$

\section{Design CONSIDERATION}

To verify the principle of the proposed converter shown in Fig. 1, a $200 \mathrm{w}$ prototype converter is constructed in the laboratory. The experimental results are obtained with the following parameters:

$\begin{array}{ll}\text { Input dc voltage range } & V_{i n}=120-190 \mathrm{~V} \\ \text { Output voltage } & V_{O}=12 \\ \text { Rated output current } & I_{O}=20 \mathrm{~A} \\ \text { Switching frequency } & f_{s}=100 \mathrm{kHz} \\ \text { Maximum duty cycle } & D_{\max }=.45 \\ \text { Turns ratio } & \mathrm{n}=76: 4 \\ \text { Clamping capacitances } & C_{1}=C_{2}=2.2 \mathrm{uF} \\ \text { Output capacitance } & C_{O 1}=C_{O 2}=330 \mathrm{uF} \\ \text { Conversion efficiency } & \eta \geq .8\end{array}$

Fig. 4 shows the experimental results of the gate signal, the leakage inductance current $i_{L r}$ and the switch currents $i_{Q 1}$ and $i_{Q 2}$. Before $Q_{1}$ is turned on, $i_{L r}$ is equal to the current $i_{Q 2}$. The negative $i_{L r}$ discharges the output capacitor $C_{r}$ across $Q_{1}$ in order to achieve ZVS operation in the dead time. After $Q_{1}$ is turned on, the primary current $i_{L r}$ is equal to the current $i_{Q 1}$.

Fig. 5 illustrates the measured results of the clamping capacitor voltages $V_{C 1}$ and $V_{C 2}$. It is shown that when $Q_{2}$ is turned on the clamping capacitor is resonating with the resonant inductor.

Fig. 6 shows the ZVS operation for $Q_{1}$, in full load and half load conditions. Fig. 5(a) and (c) show the measured results of the gate-to source and the drain-to-source voltages for $Q_{1}$. It is seen that before the gate voltage of $Q_{1}$ is turned on, the drain to- source voltage vDS1 is zero. Therefore, $Q_{1}$ is turned on under ZVS. Fig. 5(b) and (d) give the measured waveforms of the gate voltage and the drain current for $Q_{1}$. It can be observed that the drain current is negative before the gate voltage $v_{G S 1}$ is positive. The intrinsic body diode of $Q_{1}$ is conducting the negative drain current $i_{Q 1}$, and the switch

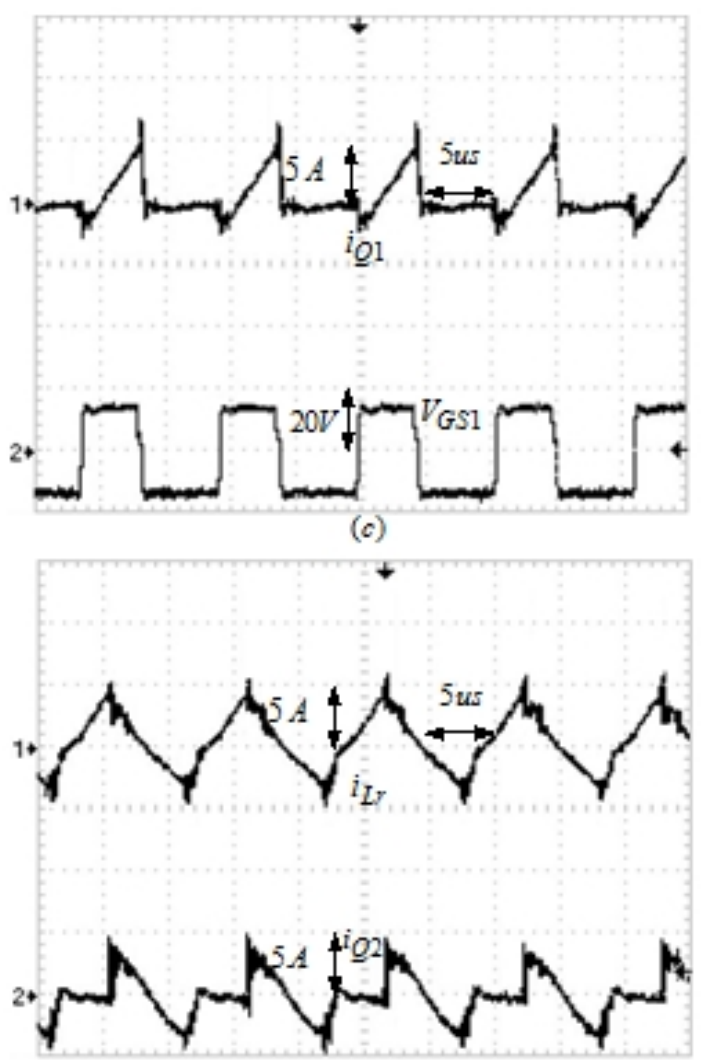

(d)

Fig. 4. Waveforms of iQ1, iQ2, VGS1, ilr.

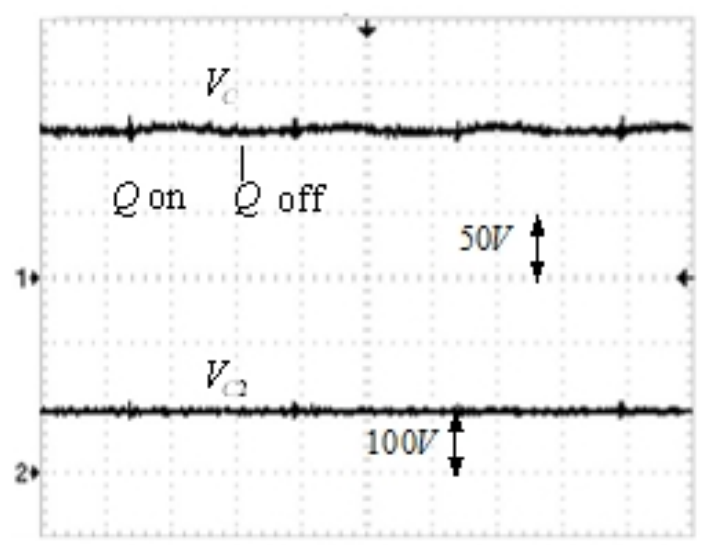

Fig. 5. Waveforms of clamping capacitor VC1and VC2.

$Q_{1}$ is turned on to ensure ZVS operation. In the same manner, the measured gate voltage, the drain voltage and the switch current of Q2 are shown in Fig. 7.

Fig. 8 shows the experimental results for the secondary-side currents $i_{D 1}$ and $i_{D 2}$ for different loads. When $Q_{1}$ is turned on the secondary-side current $i_{D 2}=i_{C O 2}+I_{O}$ and $i_{D 1}=0$. On the other hand, $i_{D 1}=i_{C O 1}+I_{O}$ and $i_{D 1}=0$ when $Q_{2}$ is on and $Q_{1}$ is off.

Fig. 9 shows the measured efficiencies of the proposed interleaved active-clamping ZVS forward-flyback converter without an output inductor at different load levels. The average efficiency is above $87.8 \%$. Under the rated full load, the conversion efficiency is about $86 \%$. 


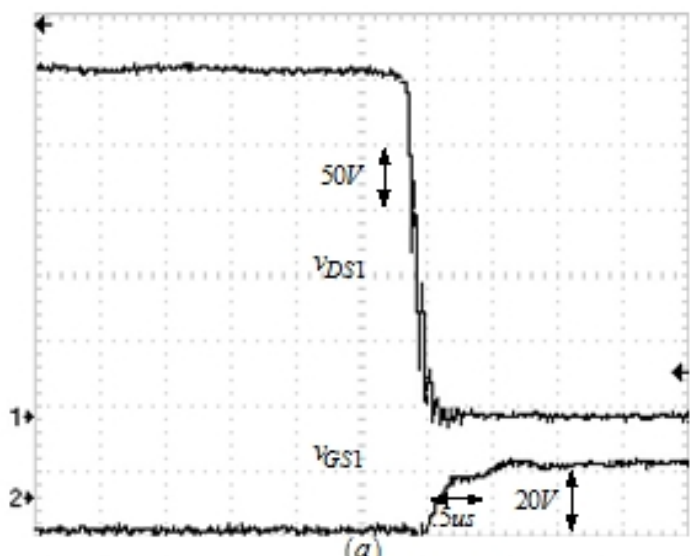

(a)
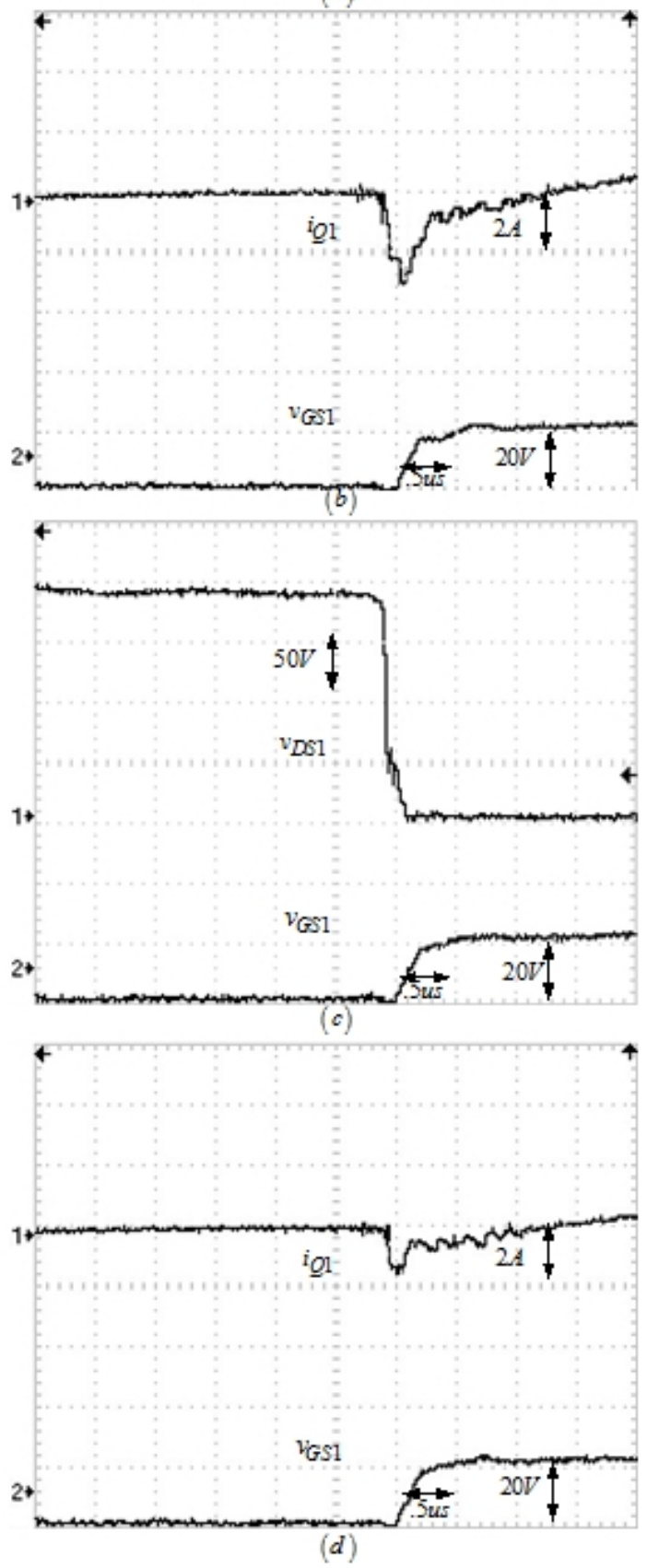

Fig. 6. ZVS operation for Q1, a, b at full load and c, d at half load.
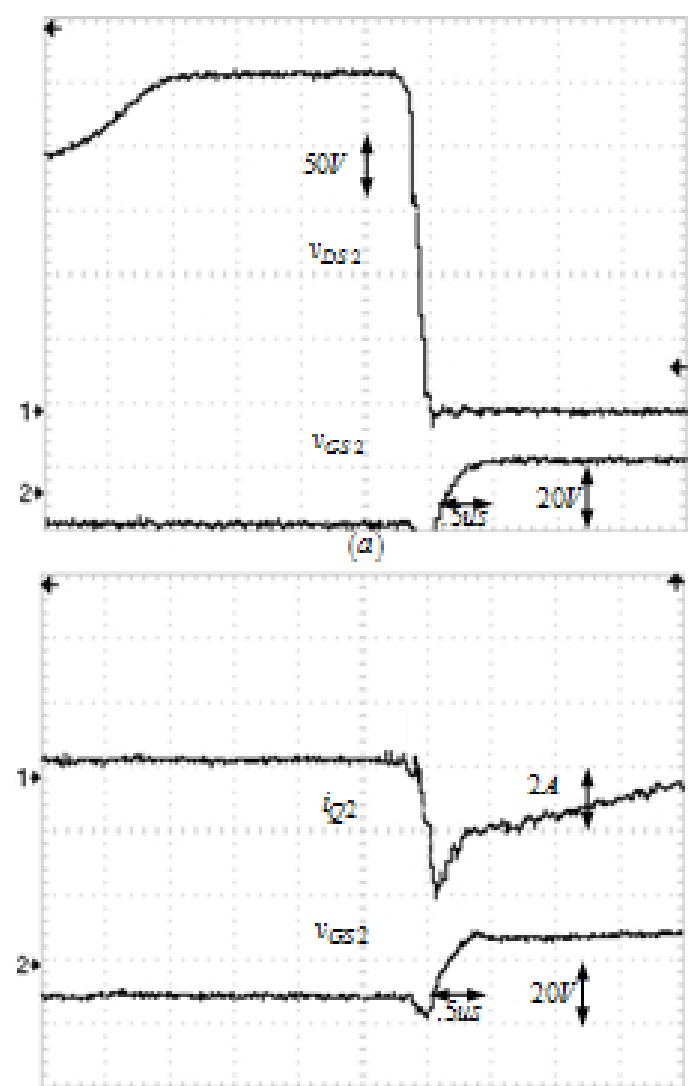

(b)
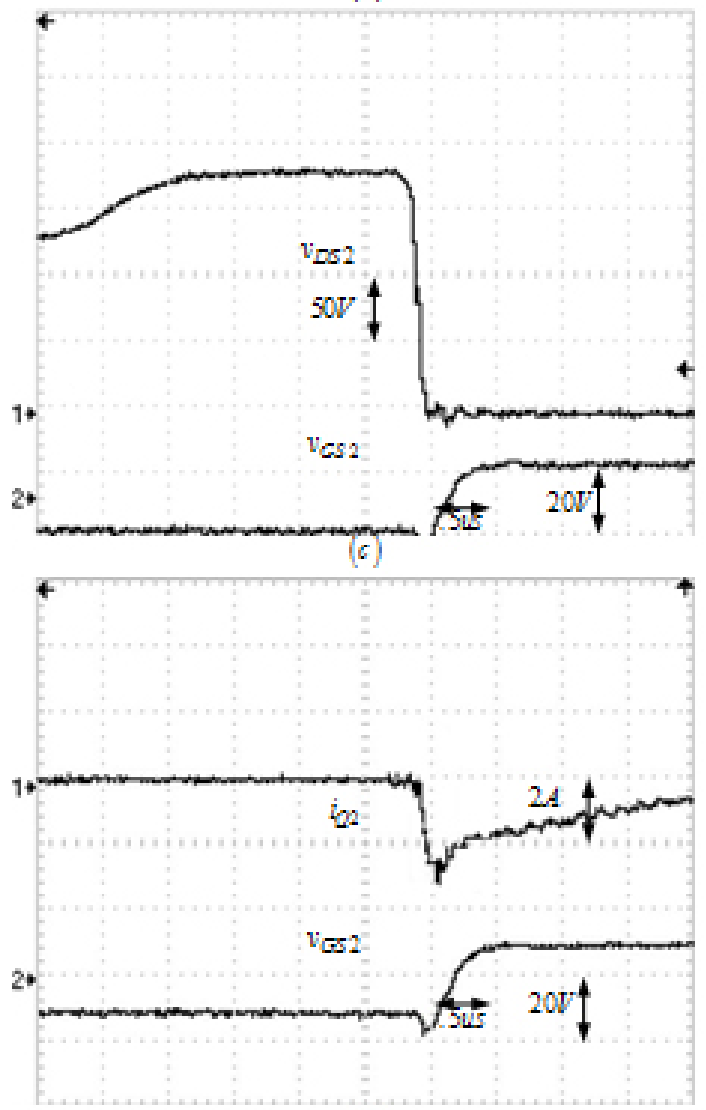

(d)

Fig. 7. ZVS operation for Q2, a, b at full load and c, d at half load. 


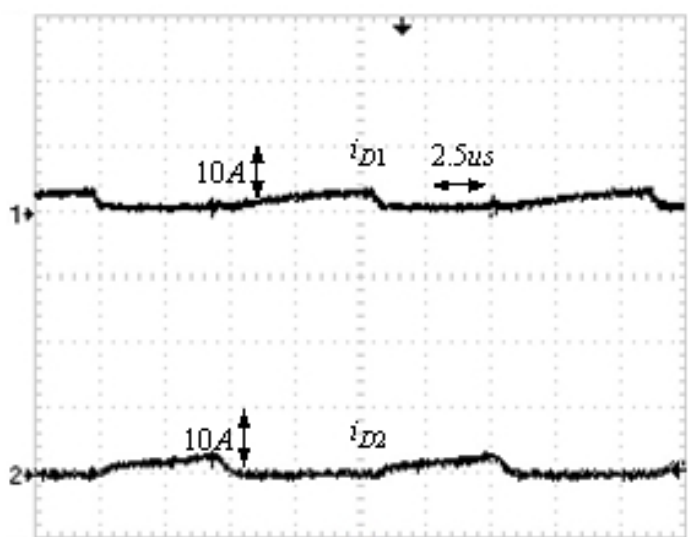

(a)

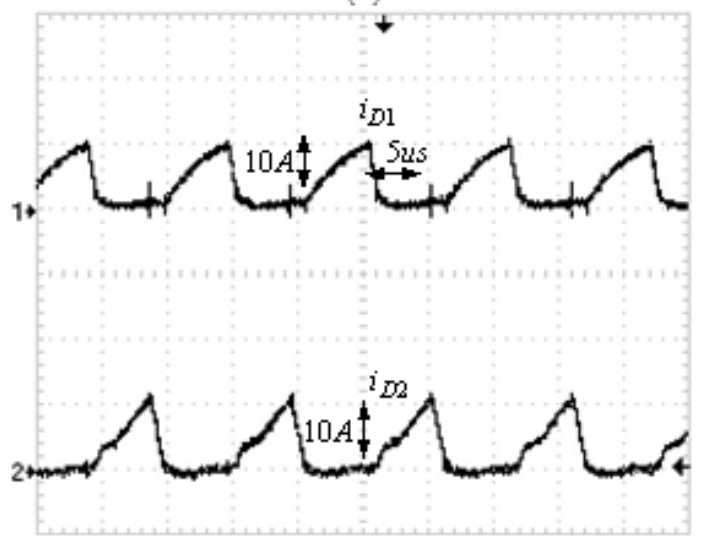

(b)

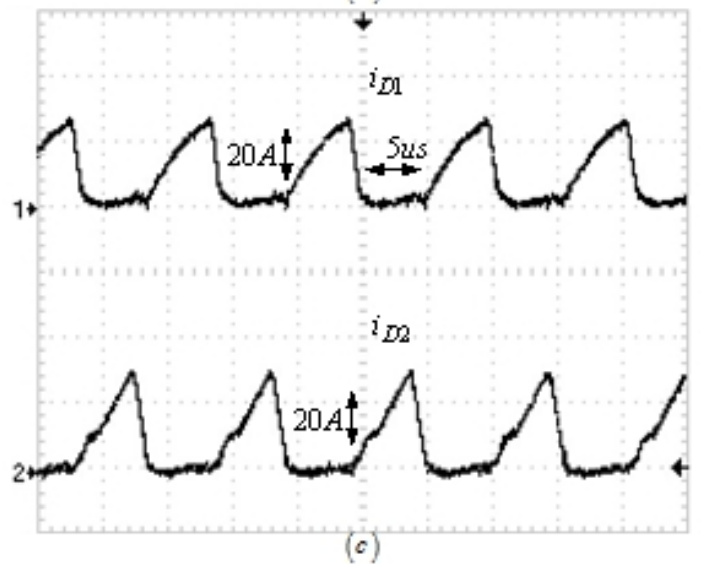

(c)

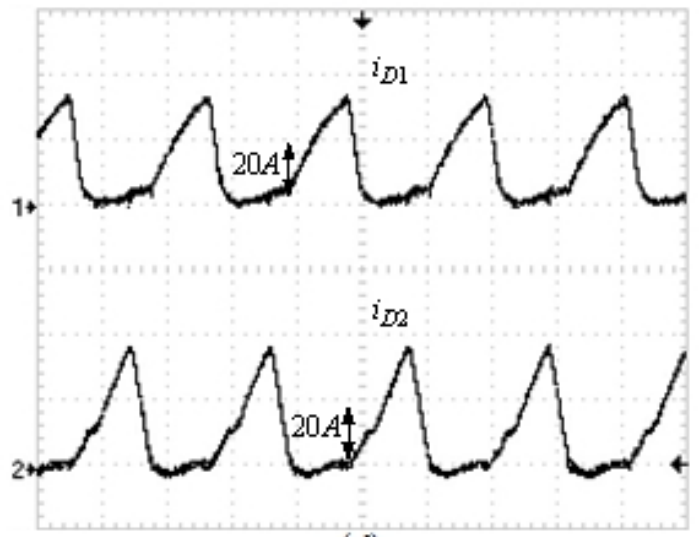

(d)

Fig. 8. Waveforms of iD1 and iD2 at a load current of (a) 2A, (b) 5A, (c) $10 \mathrm{~A}$, (d) $16 \mathrm{~A}$.

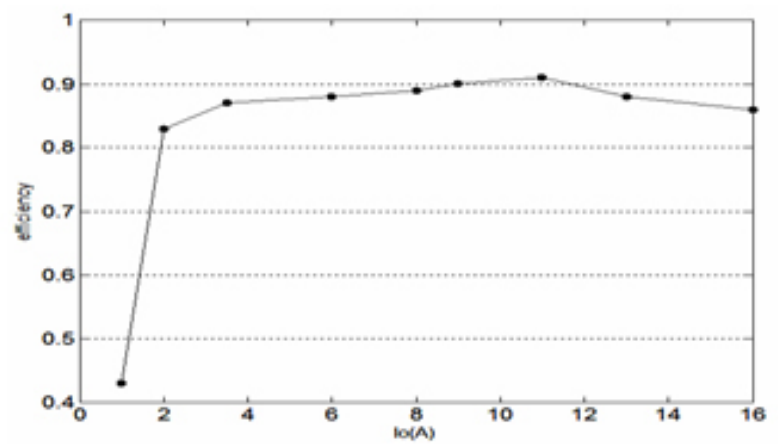

Fig. 9. Efficiencies of the proposed converter at different output current.

\section{REFERENCES}

[1] C. S. Leu, G. Hua, F. C. Lee, and C. Zhou, "Analysis and design of RCD clamp forward converter," in Proc. HFPC, pp. 198-208, 1992.

[2] F. D. Tan, "The forward converter form the classic to the contemporary," in Proc. APEC, Vol. 1, pp. 857-863, 2002.

[3] A. K. S. Bhat, F. D. Tan, "A unified approach to characterization of PWM and quasi-PWM switching converters topological constraints, classification, and synthesis," IEEE Trans. Power Electron., Vol. 6, No. 4, pp. 719-726, Oct. 1991

[4] C. P. Henze, H. C. Martin, and D. W. Parsley, "Zero-voltage switching in high frequency power converters using pulse width modulation," in Proc. APEC, pp. 33-40, 1988.

[5] R. Watson, F. C. Lee, and G. C. Hua, "Utilization of an active-clamp circuit to achieve soft switching in flyback converters," IEEE Trans. Power Electron., Vol. 11, No. 1, pp. 162-169, Jan. 1996.

[6] P. Aiou, A. Bakkali, I. Barbero, J. A. Cobos, and M. Rascon, "A low power topology derived from flyback with active clamp based on a very simple transformer," in Proc. APEC, pp. 1-6, Mar. 2006.

[7] Y. Y. Wen, H. Mao, and I. Batarseh, "DC bias analysis and small signal characteristic of active-clamp forward-flyback dc-dc converter with a current doubler rectifier, in Proc," in Proc. APEC, pp. 1531-1536, 2005.

[8] N. P. Papanikolaou and E. C. Tatakis, "Active voltage clamp in flyback converters operating in CCM mode under wide load variation," IEEE Trans. Ind. Electron., Vol. 51, No. 3, pp. 632-640, Jun. 2004.

[9] M. Chen and J. Sun, "Reduced-order averaged modeling of active clamp converters," IEEE Trans. Power Electron., Vol. 21, No. 2, pp. 487-494, Mar. 2006.

[10] B. R. Lin, H. K. Chiang, and C. C. Chen, "Analysis of a zero-voltage switching converter with two transformers," IEEE Trans. Circuits Syst. II, Vol. 53, No. 10, pp. 1088-1092, Oct. 2006.

[11] Y. H. Kang, B. C. Choi, and W. S. Lim, "Analysis and design of a forward-flyback converter employing two transformers," in Proc. PESC, pp. 357-362, 2001

[12] Y. H. Xi and P. K. Jain, "A forward converter topology employing a resonant auxiliary circuit to achieve soft switching and power transformer resetting," IEEE Trans. Ind. Electron., Vol. 50, No. 1, pp. 132-140, Feb. 2003.

[13] B. R. Lin, K. Huang, and D. Wang, "Analysis design and implementation of an active clamp forward converter with synchronous rectifier," IEEE Trans. Circuits Syst. I, Vol. 53, No. 6, pp. 1310-1319, Jun. 2006.

[14] S. S. Lee, S. W. Choi, and G. W. Moon, "High-efficiency active clamp forward converter with transient current build-up (TCB) ZVS technique," IEEE Trans. Ind. Electron., Vol. 54, No. 1, pp. 310-318, Feb. 2007.

[15] B.-R LIN, C.-H. TSENG, "Analysis of parallel-connected asymmetrical soft-switching converter," IEEE Trans. Ind. Electron., Vol. 54, No. 3, pp. 1642-1653, Jun. 2007.

[16] R. T. Bascope and I. Barbi, "A double ZVS-PWM active-clamping forward converter: Analysis, design and experimentation," IEEE Trans. Power Electron., Vol. 16, No. 6, pp. 745-751, Nov. 2001.

[17] B.-R. LIN, H.-K. CHIANG, "Analysis and implementation of a soft switching interleaved forward converter with current doubler rectifier," in Proc. IET - Electr. Power Appl., Vol. 1, No. 5, pp. 697-704, 2007.

[18] T. Jin, W. Zhang, A. Azzolini, and K. M. Smedley, "A new interleaved forward converter with inherent demagnetizing feature," in Proc. IAS, Vol. 1, pp. 625-630, 2005.

[19] W. LI, X. HE, "ZVT interleaved boost converters for high efficiency, high step-up DC-DC conversion," in Proc. IET Electr. Power Appl., Vol. 1, No. 2, pp. 284-290, 2007. 
[20] B.-R. Lin W.-C. Li K.-L. Shih, "Analysis and implementation of a zero voltage switching bi-forward converter," IET Power Electronics, Vol. 2, No. 1, pp. 22-32, Jan. 2009.

[21] J.-P. Lee, B.-D. Min, T.-J. Kim, D.-W. Yoo, and J.-Y. Yoo, "Input-SeriesOutput-Parallel Connected DC/DC Converter for a Photovoltaic PCS with High Efficiency under a Wide Load Range," Journal of Power Electronics, Vol. 10, No. 1, pp. 9-13, Jan. 2010.

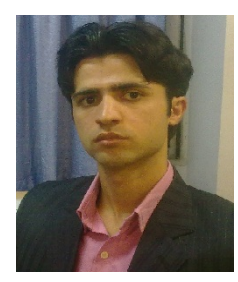

Meghdad Taheri was born in Choram, Iran, in 1984. He received his B.S. in Electrical Engineering from Shiraz University, Shiraz, Iran, in 2006, and his M.S. from the Amirkabir University of Technology (Tehran Polytechnic University), Tehran, Iran in 2010. He is currently working toward his Ph.D. at the Amirkabir University of Technology. His research interests include switching power supplies, power electronics, electrical machines and drives.

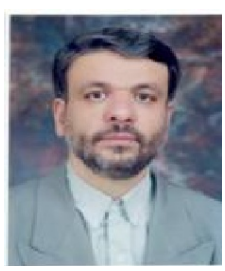

Jafar Milimonfared received his B.S. in Electrical Engineering from the Amirkabir University of Technology, and both his M.S. and Ph.D. from Paris VI University, Paris, France in 1981 and 1984, respectively. He joined the Amirkabir University of Technology as an Assistant Professor in 1984, where he is now a Professor of Electrical Engineering. From 1990 to 1993 and from 1997 to 2005, he was the Deputy of Ministry of Science, Research and Technology in Iran. He is now the Head of the Iran Mechatronics Society and the Head of Iran's Society for Morality in Science and Technology. His research interests include the design and analysis of electrical machines, power electronic and variable speed drives.

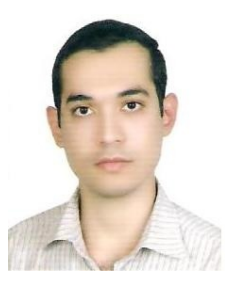

Alireza Namadmalan was born in Ahvaz, Iran, in 1987. He received his B.S. and M.S. in Electrical Engineering from the Isfahan University of Technology (IUT), in 2009, and the Amirkabir University of Technology, Tehran, Iran, in 2011, respectively, where he is currently pursuing his Ph.D. His research interests include induction heating, resonant converters, switching power supplies, electrical machines and drives, magnetic and high frequency transformers.

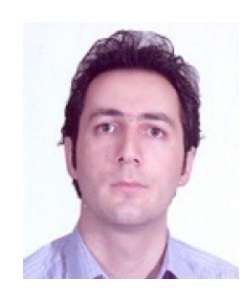

Hasan Bayat was born in Zanjan, Iran, in 1985 . He received his B.S. and M.S. in Electrical Engineering from Guilan University, Rasht, Iran, in 2008 and the Amirkabir University of Technology (Tehran Polytechnic), Tehran, Iran, in 2011, respectively. His research interests include power electronics, multilevel inverters and DC-DC power converters.

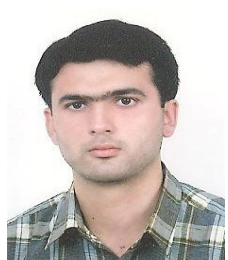

Mohammad Kazem Bakhshizadeh was born in Tehran, Iran, on April 30, 1986. He received his B.S. and M.S. in Electrical Engineering from the Amirkabir University of Technology, Tehran, Iran, in 2008 and 2011, respectively. His research interests include multilevel inverters, power electronics and power quality. 